\title{
MODERNISASI DHARMA PEMACULAN DAN IMPLIKASINYA TERHADAP PENDIDIKAN KEAGAMAAN HINDU
}

\author{
Oleh: \\ Ni Made Indiani, I Wayan Winaja, I Ketut Winantra \\ indianimade@gmail.com; winaja1962@gmail.com; ketutwinantra@unhi.ac.id. \\ Program Pascasarjana Universitas Hindu Indonesia \\ Jalan Sangalangit Tembau Denpasar. Bali
}

Proses Review 15-26 Agustus, Dinyatakan Lolos 10 September

\begin{abstract}
Modernization is changing human behavior so fast there is even a pragmatic tendency. Modern science promises conveniences to humans so that many people who want to be fast and practical. This also affects the mindset, attitudes and behavior of the people, which in turn has an impact on the shift in human civilization. This shift also occurred in the agricultural sector, which in the beginning of agriculture in Bali was done traditionally and full of kinship (dharma pemaculan) has now moved the way, namely with the green revolution that offers more and faster crops.This paper will discuss one thing, namely the implications of the shifting substance of Dharma Pemaculan to the Hindu religious education system in Bali, using the theory of Dharma Pemaculan, and Critical Education Theory. The results of this study are expected to contribute to the thought of phenomena that occur in agrarian societies, especially those that have implications for Hindu religious education based on the preservation of local culture.
\end{abstract}

Keywords: modernization, dharma pemaculan, green revolution, Hindu religious education system

\section{Abstrak}

Modernisasi mengubah perilaku manusia serba cepat bahkan ada kecenderungan pragmatis. Ilmu pengetahuan modern menjanjikan kemudahan-kemudahan kepada manusia sehingga banyak masyarakat yang menginginkan serba cepat dan praktis. Hal ini juga berpengaruh terhadap pola pikir, sikap dan perilaku masyarakat yang pada akhirnya berdampak pada adanya pergeseran peradaban manusia. Pergeseran ini juga terjadi pada sektor pertanian, yang pada awalnya pertanian di Bali dikerjakan secara tradisional dan penuh kekerabatan (dharma pemaculan) sekarang sudah berpindah cara, yakni dengan revolusi hijau yang menawarkan hasil panen lebih banyak dan lebih cepat. Tulisan ini akan membahas satu hal yaitu implikasi bergesernya substansi Dharma Pemaculan 
terhadap sistem pendidikan keagamaan Hindu di Bali, dengan mempergunakan teori Dharma Pemaculan dan Teori Pendidikan Kritis. Hasil penelitian ini diharapkan dapat memberikan sumbangan pemikiran terhadap fenomena yang terjadi pada masyarakat agraris khususnya yang berimplikasi terhadap pendidikan keagamaan Hindu yang berbasis pelestarian budaya lokal.

Kata kunci: modernisasi, dharma pemaculan, revolusi hijau, sistem pendidikan keagamaan Hindu

\section{PENDAHULUAN}

Kabupaten Tabanan adalah salah satu Kabupaten dari delapan Kabupaten, dan satu Kota yang ada di Propinsi Bali. Kabupaten Tabanan terletak di wilayah bagian Barat Daya Pulau Bali. Kabupaten Tabanan memiliki luas wilayah 839,33 $\mathrm{KM}^{2}$ atau 14,90 persen dari luas Propinsi Bali yaitu seluas 5.632,86 Km², yang terdiri dari daerah pegunungan, daratan datar, dan pantai. Secara geografis wilayah Kabupaten Tabanan terletak antara $1140^{\circ}-54^{0,} 52^{\circ}$ bujur timur dan $8014^{\circ}, 30^{\circ}-8030^{\circ} 07^{\circ}$ lintang selatan. Sebanyak 23.358 Ha atau 28,00 persen dari luas lahan yang ada di Kabupaten Tabanan merupakan lahan persawahan, sehingga Kabupaten Tabanan dikenal sebagai daerah agraris, dan dikenal pula sebagai Kabupaten lumbung padi di Provinsi Bali.

Potensi unggulan Kabupaten Tabanan adalah bidang pertanian dan dijadikan sebagai soko guru perekonomian daerah, karena penggunaan lahan di Kabupaten Tabanan yang didominasi pada bidang pertanian dalam arti luas, yang tersebar di 10 Kecamatan. Kabupaten Tabanan terdiri dari 10 Kecamatan yaitu : 1) Kecamatan Tabanan; 2) Kecamatan Kediri; 3) Kecamatan Kerambitan; 4) Kecamatan Selemadeg; 5) Kecamatan Selemadeg Barat; 6) Kecamatan Selemadeg Timur; 7) Kecamatan Penebel; 8) Kecamatan Pupuan; 9)Kecamatan Marga; 10) Kecamatan Baturiti.

Menurut Koentjaraningrat (2004) budaya agraris adalah kebiasaan sekelompok individu yang menetap di suatu daerah dan menggantungkan hidupnya pada bercocok tanam atau bertani baik di sawah maupun di kebun. Kehidupan masyarakat Indonesia khususnya di Bali masih jauh dari kehidupan modern dengan kata lain masih hidup sederhana secara tradisional.
Revolusi Hijau di Indonesia dimulai sejak berlakunya UU Agraris tahun 1870 yang dikeluarkan pemerintah Kolonial Belanda. Dalam perkembangannya kemudian, pada masa Orde Baru program revolusi hijau digunakan sebagai salah satu cara untuk meningkatkan produksi pangan di Indonseia, terutama produksi beras. Usaha yang dilakukan dalam revolusi Hijau adalah melakukan gerakan mengubah pola pertanian tradisional ke "modern", di Indonesia disebut dengan istilah Panca Usaha Tani.

Dalam penelitian ini yang dimaksud Revolusi Hijau adalah gerakan mengubah substansi cara bertani tradisional ke modern (Hartono, Mudji, 2014). Program revolusi hijau di masa lalu dilakukan melalui pendekatan program Bimas, Inmas, Insus, dan Panca Usaha Tani, yang menekankan pada peningkatan produksi hasil usaha tani. Hal itu tidak lepas dari kebijakan pemerintah di bidang pertanian untuk mewujudkan swasembada pangan. Sebuah cara yang belakangan mulai disadari beresiko menimbulkan berbagai macam penyakit karena tingginya kandungan kimia beracun pada bahan pangan dan merusak lingkungan.

Rusaknya lingkungan berdampak pada hilangnya budaya pertanian seperti nyuluh, nyapung, nyeser, mekena bubu, dan sebagainya. Kehidupan sosial budaya orang Bali pun berubah. Semua ingin serba cepat dan tak sempat lagi melakukan pendalaman secara rasa, etika, dan estetika sesuai spirit dan filosofi Sad Kertih dan Dharma Pemaculan. Petani pun lebih mementingkan hasil dari pada menghormati cara-cara alami. Cara-cara bertani yang merusak alam akhirnya secara tidak langsung berdampak pada tingkat kenyamanan kehidupan. Terjadi penggantian varitas padi dari padi lokal yang berumur enam bulan dengan jenis padi baru (PB) dengan umur 4 bulan juga memiliki 
dampak terhadap pola tanam. Petani jadi lebih sibuk di sawah demi mengejar target-target ekonomi.

Tulisan ini akan menelaah implikasi modernisasi bertani (dharma pemaculan) melalui revolusi hijau terhadap pendidikan keagamaan Hindu. Adapun teori yang dipergunakan adalah teori Dharma Pemaculan dan Teori Pendidikan Kritis. Kontribusi yang diharapkan dari tulisan ini adalah kontribusi pemikiran agar upacara-upacara keagamaan yang dilakukan dalam bertani masih tetap dilakukan untuk dapat memberikan pengetahuan yang bermanfaat kepada generasi muda khususnya tentang pendidikan keagamaan.

\section{METODE PENELITIAN}

Pengumpulan data dalam penelitian kualitatif bersifat, emik post priori, dan holistik kontekstual (Ulfatin, 2013). Dikatakan emik post-priori karena penelitian ini berupaya menemukan makna atas realitas sosial yang terjadi, yang sifatnya subyektif pada petani yang ada di kabupaten Tabanan. Data yang diperoleh tidaklah bersifat menguji teori-teori yang telah ada, melainkan memberi pemaknaan atas data yang diperoleh. Dengan demikian data yang dicari pada penelitian kualitatif sifatnya lebih kompleks dan beragam serta dapat menginterpretasi atau memberi makna tidak saja terhadap data yang nampak (kasat mata) namun juga yang tersirat (holistik kontekstual). Dengan mempergunakan teknik snow ball untuk memperoleh data yang sebanyak-banyaknya di lapangan terkait dengan konteks penelitian maka dipergunakan teknik observasi, teknik wawancara mendalam, teknik studi dokumen.

\section{III . PEMBAHASAN}

\subsection{Filosofi Sad Kertih dan Dharma Pemaculan}

Dalam bingkai tatanan Sad Kertih dapat dijelaskan sebagai berikut (1) Atman Kertih"(penyucian jiwa) kepada seseorang dari Sang Pencipta atau alam semesta (leluhur). Dengan melaksanakan Atman Kertih, seseorang akan memiliki jiwa yang bersih dan selaras dengan alam lingkungan dimana ia beraktivitas. Hal itu merupakan pola hubungan antara parahyangan, palemahan dan pawongan harus menyatu dalam satu keyakinan yang seimbang (Tri Hita Karana); (2) Jana Ketih, yaitu membangun kesadaran dengan jiwa yang mulai menyatu dengan alam lingkungan di sawahnya, seperti pengetahuan bahwa, tikus tidak perlu dimusuhi. Tikus harus dihormati sebagai bagian dari mahluk hidup. Tikus merusak padi karena diyakini ekosistem di sebuah kawasan tidak seimbang lagi; (3) Wana Kertih, dengan pengetahuan lokal yang perlu diperhatikan, seperti menanam beberapa tanaman ketela, ubi di sekitar sawahnya. Wana dalam filosofi ini adalah bermakna hutan atau tumbuhan. Hal itu dimaksudkan agar tikus-tikus juga memperoleh makanan sehingga tidak merusak padi; (4) Danu Kerti, terkait dengan kualitas air yang baik, yang akan berdampak pada peningkatan kesuburan tanah. Kondisi air dan tanah yang minim zat beracun membuat hewan sawah kembali muncul seperti; kakul, belauk, capung, katak dan ular. Untuk menjaga kualitas air dan terjaganya kesuburan harus menggunakan pupuk alami buatan sendiri "Mikroba Olah Lokal (MOL).

Semua itu pulih karena adanya upaya pemeliharan kualitas air; (5) Segara Kertih, makna Segara Kertih di sini adalah sebuah "gerak alam" yang mensejahterakan seperti gerak air, gerak udara, suara, aktivitas dan sebagainya. Dengan pulihnya ekosistem sawah akibat adanya pemeliharaan air, tanah, tumbuhan di sawah menyebabkan suasana pertanian menjadi indah dan menarik, terbangun suasana peningkatan rasa, dan estika. Karena suasana menyenangkan maka apapun yang dikerjakan tidak cepat membuat lelah dan menjenuhkan;

(6) Jagat Kertih, makna "jagat" di sini adalah semesta baik dalam wilayah kesadaran parahyangan, palemahan atau pawongan. Terpeliharanya alam lingkungan yang seimbang akan terjadi jika pola kehidupan manusia masih menjalankan dan meyakini kelima kertih di atas. Jelas kesadaran dan keyakinan kehidupan yang senantiasa menjalankan spirit dan tatanan Sad Ketih akhirnya membuktikan filosofi kehidupan dan budaya masyarakat Bali adalah Tri Hita Karana, (tiga penyebab kesejahteraan) yang 
terbangun dari harmonisannya hubungan yang seimbang antara manusia dengan Tuhan, hubungan manusia dengan manusia, dan hubungan antara manusia dengan alam lingkungan.

Spirit Sad Kertih yang dalam filosofi budaya Bali diyakini sebagai enam unsur dasar sebagai sumber kesejahteraan umat manusia. Apapun yang dilakukan oleh umat manusia wajib diawali dengan proses penyucian jiwa (Atman Kertih). Dalam masyarakat pertanian dan aktivitas budaya agraris di Bali hal itu masih nyata dan mudah kita lihat. Beragamnya upacara yadnya (panca yadnya) bukan lah tanpa makna. Upacara yadnya adalah proses untuk selalu menyucikan jiwa semua makluk. Termasuk tikus, serangga dan sebagainya. Sehingga keberadaan tikus, serangga atau hewan lain di sawah tidak berubah menjadi hama atau "mrana". Beberapa aktivitas yadnya (Dharma Pemaculan) yang kerap dilakukan oleh petani yaitu upacara yang berkaitan dengan air seperti: nangluk merana, pekelem di danu, ngusabha di ulun danu dan magpag toya atau mendak toya. Sedang upacara yang berkaitan dengan tanaman padi adalah: Mantenin somi, ngawit mungkah ngendang, ngurit, nwasen, nandur dan masih banyak lagi rentetan upacara lainnya.

Secara filosofis dapat kita simpulkan bahwa kehidupan yang masih meyakini dan menghormati sepirit dan hukum alam akan melahirkan masyarakat yang berbudaya. Hal itu ditunjukan oleh aktivitas bertani di Bali relatif masih meyakini dan menjalankan tahapan yadnya di atas.

\subsection{Teori Pendidikian Kritis}

Menurut Undang-undang Sistem Pendidikan Nasional No. 20 Tahun 2003 disebutkan bahwa Sistem Pendidikan adalah usaha sadar dan terencana untuk mewujudkan suasana belajar dan proses pembelajaran agar peserta didik secara aktif mengembangkan potensi dirinya untuk memiliki kekuatan spiritual keagamaan, pengendalian diri, kecerdasan, ahlak mulia serta ketrampilan yang diperlukan bagi dirinya, masyarakat, bangsa, dan Negara. Sedangan pendidikan keagamaan yang dimaksud dalam penelitian ini adalah sistem pendidikan keagamaan Hindu. Pendidikan menurut Hindu memiliki tujuan mengubah seseorang yang biasa (manawa), menjadi manusia yang mempunyai nilai kebajikan lebih tinggi (madhawa) manusia setengah dewa. Madhawa akan dapat melahirkan keunggulan moral, dengan spiritsvaha, dhavala, nihsesa jadyapakah, dan devalaya, yang sanggup menjunjung kebenaran, mewujudkan kemurnian pikiran, kesucian jiwa, serta menghargai manusia sebagai tempat pemujaan Tuhan (Sedyawati, 1991; Siva, 2003).

Di dalam kebudayaan Yunani Kuno, pendidikan diilustrasikan sebagai pengolahan tanah pertanian di mana benih dapat tumbuh dengan sempurna dan menghasilkan buah. Dari ilustrasi ini pendidikan dimaknai sebagai usaha terpadu untuk memanusiakan manusia muda, membentuk karakter sehingga menjadi pribadi yang berkeutamaan, dan terpandang karena memiliki budaya intelektual. Dengan kata lain pendidikan adalah proses humanisasi, dalam arti mengolah potensi-potensi yang dimiliki seseorang untuk menjadi lebih manusiawi. Pendidikan juga dapat dipahami sebagai proses liberalisasi dalam arti bahwa melalui pendidikan potensi-potensi seseorang mengalami proses emansipasi dan pembebasan dari pelbagai bentuk penindasan dogmatis dan fatalisme yang melumpuhkan. Melalui pendidikan, seseorang dibentuk dan dibekali pengetahuan dan ketrampilan sehingga ia mampu mengembangkan potensinya untuk menjadi agen pembebasan bagi dirinya, dan bagi orang lain, serta lingkungannya. Pendidikan merupakan media untuk mencerdaskan kehidupan dan membawa manusia ke era pencerahan, memberikan pembukaan dan perluasan pengetahuan sehingga dapat mewujudkan melek terhadap kehidupan. Dengan demikian pendidikan tidak hanya usaha pemberian informasi dan pembentukan ketrampilan untuk persiapan kehidupan yang akan datang, tetapi juga untuk menuju kehidupan yang dewasya (dewasa), pradnyan (cerdas) secara intelektual, emosional, dan spiritual, serta mampu merasakan segala keluh kesah yang berada di sekitarnya. (Gandhi, H.W, 2011: 19-20; Tarpin, 2008: 343-350).

Umat manusia perlu masa belajar yang panjang sebagai persiapan untuk dapat secara 
tepat dan konstruktif berhubungan dengan lingkungan. Dimulai dari anak manusia mencapai penyesuaian jasmani (dapat bejalan sendiri, makan sendiri, menggunakan tangan sendiri) atau mencapai kebebasan fisik. Manusia harus dan wajib dididik, sebab kalau tidak ia akan kehilangan hakekat kemanusiaannya, dan akan menjadi tidak berbudaya. Sebagai sarana utama untuk memajukan kehidupan, pendidikan memberi tuntunan, bantuan, dan pertolongan kepada umat manusia. Pengertian memberi tuntunan, bantuan, dan pertolongan pada sistem pendidikan persekolahan, tersimpul suatu dasar pengakuan bahwa anak memiliki delapan potensi (kecerdasan) untuk berkembang. Potensi-potensi yang teridentifikasi yaitu 1) potensi linguistik; 2) potensi matematika; 3) potensi visual/spasial; 4) potensi kinestetik/perasa; 5) potensi musikal; 6) potensi interpersonal; 7) potensi intrapersonal; 8) potensi intuisi. Potensi ini secara berangsur-angsur tumbuh dan berkembang dalam diri anak. Untuk berkembangnya potensi-potensi (kecerdasan) agar menjadi lancar dan terarah, diperlukan pertolongan, tuntunan dari luar yaitu pedidikan persekolahan. Jika pertolongan tidak ada, maka potensi/kecerdasan tersebut tinggal potensi belaka yang tak sempat diaktualisasikan. Dalam hal ini pendidikan harus memberikan keseimbangan aktivitas terhadap otak kanan dan otak kiri sehingga kecerdasan antara logika dan rasa menjadi padu dan seimbang. Pendidikan harus bersifat utuh dan komprehensif, harus mampu mengembangkan nalar, dan harus juga mampu mengembangkan potensi rasa. (Hernacki, 2003:31- 38; Ihsan, 1996:2; Suprayogo, 2013: XVI; Tarpin, 2008: 343-345).

Pendidikan yang baik adalah pendidikan yang dapat menghasilkan individu yang dapat mempertahankan dan meningkatkan mutu hidupnya. Hal ini terjadi apabila bentuk kegiatan pendidikan mempunyai tujuan yang tepat. Dalam konteks ini pendidikan adalah proses transformasi diri dari sikap ignorant menuju kesadaran kritis atas apa yg terjadi dalam diri dan lingkungannya. Disamping itu dapat dijadikan sebagai wahana pemberdayaan manusia untuk menjadi agen perubahan sosial.
Melalui pendidikan yang transformatif dan partisipatif, diharapkan mampu mengembangkan dimensi individual dan sosial secara seimbang. Pendidikan yang rumusan tujuannya tidak tepat akan memunculkan tujuan pendidikan yang tidak benar pula. Tujuan pendidikan dikatakan tidak benar apabila berisi nilai-nilai hidup yang bersifat mengingkari dan merusak harkat dan martabat manusia sebagai makhluk sosial, individual, serta hamba Tuhan Yang Maha Esa.

Saat ini pendidikan persekolahan telah dipercaya menjadi sesuatu yang diterima sebagai kebenaran aksiomatis, dipandang sebagai sesuatu yang penting serta mesti ada dalam keberlangsungan hidup manusia di mana pun berada dari waktu ke waktu. Kepercayaan ini begitu klasik sehingga sulit bagi siapapun untuk mengetahui sejak kapan manusia mulai menaruh optimisme dan kepercayaannya pada pendidikan persekolahan. Di Eropa misalnya, keyakinan dan kepercayaan terhadap pendidikan persekolahan, kemudian memunculkan sesuatu seperti school, pedagogie, education, dan andragogie. Sementara di dunia Timur ditemukan juga hal yang sama seperti madrasah, pesantren, padepokan, grahavidya, pesraman, yang semuanya merujuk pada tempat atau wahana pendidikan (Gandhi, H.W, 2011: 19-20; Mudyahardjo (2001:37).

Melalui sistem school, pedagogie, education, dan andragogie, lulusan lembaga pendidikan saat ini, menjadi profesional, tetapi tidak atau kurang peduli terhadap tanggung jawab etisnya, telah muncul gejala-gejala semakin langkanya sosok pribadi yang beradab, punya wawasan generalis, seimbang kepribadiannya. Apa yang dilakuknnya sering tidak memperhatikan dampak yang sangat luas bagi orang lain dan lingkungan sekitarnya. Contoh sederhana pemanfaatan sinar laser dalam berbagai event untuk kepentingan dunia ekonomis. Dari salah satu contoh ini tersirat bahwa libido ekonomi begitu kuat pada masyarakat terdidik saat ini.

Kualitas pendidikan persekolahan, dimanifestasikan dengan kehidupan manusia yang semakin bergelimang materi. Makna kehidupan ditentukan oleh kehidupan ekonomi. Demikian pula berbagai sektor kehidupan diukur dengan nilai-nilai ekonomis. Hal ini tentu 
sangat tidak relefan bila dibandingan dengan ajaran pendidikan persekolahan, yang tersurat dalam landasan pendidikan Hindu, seperti contoh revolusi hijau. Ajaran pendidikan persekolahan menenkankan terciptanya sisya yang dewasya, sesuai ajaran Dewi Sampad. (Sedyawati, 1991; Sihiva, 1997; Winaja, 2013)

\subsection{Implikasi Pergeseran Substansi Dharma Pemaculan Terhadap Sistem Pendidikan Keagamaan di Bali}

Sebagaimana diuraian oleh Bapak I Wayan Merta Yasa (57 thn) guru Agama SMP Negeri Selemadeg; Bapak I Nyoman Sugiharta (59 thn), pengawas Agama Hindu Kabupaten Tabanan; I Ketut Widra (60 thn), juga pengawas guru agama Hindu di Kabupaten Tabanan. "Bahwa saat ini yang diutamakan adalah kepentingan ekonomi sehingga kepentingan peningkatan srada dan bhakti digeser ke nomor berikutnya, termasuk kearifan lokal pelaksanaa filosofi Dharma Pemaculan, dilanggar sehingga dalam praktek keagamaan terkait dengan Dharma Pemaculan, siswa SD, SMP, SMA/SMK, Perguruan Tinggi, hanya tahu dari media sosial. Tidak pernah merasakan bagaimana indahnya pelaksanaan Dharma Pemaculan. Hampir sebagian budaya bertani sudah mulai ditinggalkan petani di beberapa subak di wilayah Tabanan, sebagai lumbung berasnya Bali. Pendidikan keagamaan terkait Dharma Pemaculan, yang di dalamnya juga ada rasa saling asah asih asuh, konsep Tri Hita Karana menjadi relative hilang. Misalnya, budaya ngajakin ngabut bulih (bergotong royong mencabut benih padi), ngajakin memula (bergotong royong menanam padi), ngajakin mejukut (membantu membersihkan gulma tanaman padi), ngajakin manyi (membantu memanen padi), dan mebleseng (mengangkut hasil panen padi dari sawah ke rumah). Belakangan budaya tersebut sudah jarang dilakukan karena tuntutan zaman yang ingin serba praktis. Aktivitas itu sudah digantikan dengan meburuhan (memanfaatkan tenaga orang lain dengan imbalan upah). Sehingga kemudian ada istilah memburuh matekap, maburuh nanem padi, maburuh manyi dan sebagainya.

Demikian juga penggunaan sapi sebagai tenaga pembajak sawah, juga sudah mulai digantikan dengan mesin traktor. Fenomena ini dikhawatirkan akan memunahkan peralatan pembajak tradisional. Akhirnya generasi muda Bali tidak lagi mengenal istilah tengala, lampit, kaun lampit, uga, samed, tali singkal, temaja, pecut dan sebagainya. Demikian juga makhluk hidup (gumatat-gumitit) yang hidup dan berkembang di sawah, sudah mulai langka akibat penggunaan pupuk dan pestisida kimiawi yang berlebihan. Ditambah dengan makin berkurangnya ketersediaan air.

Punahnya sejumlah gumatat-gumitit itu membuat generasi muda tidak mengenal yang namanya becing-becing (anak katak), katak, godogan, blauk, jubel, cucutan, pici-pici, bingabinga, kakul, gondang, capung, jang krik, belalang, lindung (belut), уиуи dan sebagainya. Jadi dengan pendidikan keagamaan konsep Tri Hita Karana tidak jalan maka alam menjadi semakin tidak harmoni. Dulu, semua hewan sawah (dari alam) itu dijadikan menu makanan bagi petani di tengah langkanya daging yang dijual di pasar".

Seperti uraian di atas ritual terkait Dharma Pemaculan usaha tani padi masih tetap dilangsungkan di beberapa subak di Bali termasuk di Tabanan, (lokasi penelitian), tetapi tidak semarak jaman dahulu sebelum ada revolusi hijau. Misalnya, prosesi ritual mapag toya, ngewiwit, nyaeb, mesaba (ngusabha) dan mantenin padi. Dulu ketika petani masih menanam varietas padi tahun, masih terjaga harmoni hubungan manusia dengan manusia yang disebut dengan budaya mepleseng. Padi yang diikat (masigihan) itu diangkut secara gotong royong dengan cara dipikul menggunakan sanan oleh laki-laki, dan diusung (dijunjung) menggunakan keranjang oleh kaum perempuan.

Tapi belakangan petani menanam padi jenis atau varietas baru yang usianya lebih pendek, biasanya langsung diselesaikan di sawah, dalam bentuk gabah dimasukkan ke kampil, kemudian dibawa ke rumah. Bahkan, ada yang ingin praktis, padinya langsung dijual di sawah, dan uangnya dibelikan beras. Tapi, budaya mantenin padi masih dilakukan dengan membawa sedikit ke rumah kemudian diupacarai," Sejak, lima tahun lalu beberapa lahan sawahnya sudah ditanami cokelat karena minimnya air. Karena tidak menanam padi, tentu upacara seperti 
ngewiwit dan mantenin padi tidak dilakukan. Tiga tahun lalu air masih bagus. Petani bisa menanam padi, tentu upacara berhubungan dengan tanam padi masih semuanya lengkap mulai dari mapag toya, ngewinih, biyukukung, ngusaba, dan mantenin padi. Kini, karena "ngetuh" alias tidak ada air, hanya yang bisa menghasilkan padi saja yang mantenin padi. Demikian juga soal pemakaian pupuk dan pestisida kimiawi, diakui menyebabkan binatang sawah seperti katak, lindung, blauk, jubel, cucutan, pici-pici dan capung mulai langka.

\section{PENUTUP}

Modernisasi atau bergesernya dharma pemaculan ke revolusi hijau membawa pengaruh besar terhadap sistem pendidikan keagaaman, yaitu menyebabkan beberapa kegiatan keagamaan menjadi disimulakrumkan, dan generasi muda total sudah kehilangan pendidikan keagamaan dari proses bertani yang berbasis kearifan lokal Dharma Pemaculan.

\section{DAFTAR PUSTAKA}

Anonim. 2003. Undang-undang Sistem Pendidikan Nasional No. 20 Tahun 2003.

Gandhi HW, Teguh Wangsa. 2011. Filsafat Pendidikan. Jogjakarta: Ar-Ruzz Media.

Hatono, Mudji. 2014. Respon Masyarakat Sukoharjo terhadap Revoluasi Hijau. Laporan Penelitian. Universitas Negeri Yogyakarta. Diambil dari http://staff.uny.ac.id/sites/default/files/ penelitian/drs-mudji-hartono-mhum/cover-respon-masyarakat-sukoharjo-terhadaprevolusi-hijau.pdf (akses tanggal 27 Maret 2019)

Hernacki, Mike; Bobbi DePorter. 2003. Quantum Learning: Unleasing The Genius In You (Quantum Learning: Membiasakan Belajar Nyaman dan Menyenangkan). Bandung: Penerbit Kaifa.

Ihsan, Fuad. 1996. Dasar-dasar Kependidikan. Jakarta: Rineka Cipta.

Koentjaraningrat. 2004. Manusia dan Kebudayaan Di Indonesia. Jakarta: Djambatan.

Mudyahardjo, Redja. 2001. Pengantar Pendidikan Sebuah Studi Awal Tentang Dasar-dasar Pendidikan pada Umumnya dan Pendidikan di Indonesia. Jakarta: PT Raja Grafindo Persada.

Sedyawati, Edhie; Zainuddin, M; Wuyantoro. 1991. Sejarah Pendidikan Di Indonesia Sebelum Kedatangan Bangsa-bangsa Barat. Jakarta: Depdikbid, Direktorat Jarahnitra

Shiva,Vandana.1997. Bebas Dari Pembangunan. Jakarta:Yayasan Obor Indonesia bekerjasama dengan Konphalindo

Suwarsono, dan Alvin. Y.S. 1990. Perubahan Sosial dan Pembangunan Di Indonesia. Jakarta: LP3ES

Tarpin, Laurentius. 2008. Humanisme dan Reformulasi Praksisi Pendidikan. Dalam Bamabang Sugiharto (Ed). Yogyakarta: Jalasutra

Ulfatin, N.(2013). Metode Penelitian Kualitatif Di Bidang Pendidikan: Teori Dan Aplikasinya. Studi Kasus,Etnografi,Interaksi Simbolik, dan Penelitian Tindakan pada Konteks Manajemen Pendidikan. Malang : Bayupedia.

Winaja, I Wayan. 2012. " Marginalisasi Jurusan IPS dan Bahasa di Sekolah Menengah Atas : Studi Kasus Di SMA Negeri 1 Dan SMA Dwijendra Denpasar" dalam Desertasi Program Doktor (S3) Kajian Budaya. Denpasar: Pascasarjana Universitas Udayana 